\title{
Intra-household Bargaining for School Trip Accompaniment of Children: A Group Decision Approach
}

\author{
Alireza Ermagun $^{\mathrm{a}}$ and David Levinson ${ }^{\mathrm{b}}$ \\ ${ }^{a}$ Graduate Research Assistant, Networks, Economics and Urban Systems research group, University of \\ Minnesota, Department of Civil, Environmental, and Geo-Engineering, 500 Pillsbury Drive SE, Minneapolis, MN \\ 55455 USA. Email: ermag001@umn.edu (Corresponding Author) \\ ${ }^{\mathrm{b}}$ RP Braun-CTS Chair of Transportation Engineering; Director of Network, Economics, and Urban \\ Systems Research Group; University of Minnesota, Department of Civil, Environmental, and Geo-Engineering, 500 \\ Pillsbury Drive SE, Minneapolis, MN 55455 USA, Email: $\underline{\text { dlevinson@ } \text { umn.edu }}$
}




\begin{abstract}
This paper tests a group decision-making model to examine the school travel behavior of students 6-18 years old in the Minneapolis-St. Paul Metropolitan area. The school trip information of 1,737 two-parent families with a student is extracted from Travel Behavior Inventory data collected by the Metropolitan Council between the Fall 2010 and Spring 2012. The proposed model has four distinct characteristics including: (1) considering the student explicitly in the model, (2) allowing for bargaining or negotiation within households, (3) quantifying the intra-household interaction among family members, and (4) determining the decision weight function for household members. This framework also covers a household with three members, namely, a father, a mother, and a student, and unlike other studies it is not limited to dual-worker families. To test the hypotheses we developed two models, each with and without the group-decision approach. The models are separately developed for different age groups, namely students 6-12 and 12-18 years old. This study considered a wide range of variables such as work status of parents, age and gender of students, mode of travel, and distance to school. The findings of this study demonstrate that the elasticities of the two modeling approaches differ not only in the value, but in the sign in some cases. In 63 percent of the cases the unitary household model underestimates the results. More precisely, the elasticities of the unitary household model are as large as 2 times more than that of the group-decision model in 20 percent of cases. This is a direct consequence of model misspecification that misleads both long- and short-term policies where the intra-household bargaining and interaction is overlooked in travel behavior models.
\end{abstract}

Keywords: Travel behavior; Group decision; School trips; Escorting children; Model misspecification 


\section{INTRODUCTION}

The question of how individuals make decisions has yet to be satisfactorily answered. Neoclassical microeconomic theories have typically assumed either an individual or a unitary household as the basic decision unit (Fortin and Lacroix, 1993). Yet, conclusive instances have been put forward to show that individual decision-making is counterintuitive in numerous actual choice situations (Bhat and Pendyala, 2005; Zhang et al., 2009; Timmermans and Zhang, 2009). "Household" choices emanate from the decisions of individual household members who consider intra-household interactions (Ho and Mulley, 2015a; Ho and Mulley, 2015b).

Long-term decisions, such as residential location and car ownership, may include a negotiation process within household members. In a dual-earner household, for instance, each worker has preferences, intensity, and constraints. Short-term decisions, like daily activity travel patterns including activity participation, chauffeuring, and activity scheduling, may be thought of as containing a collective model framework. In a nuclear family with a student, for example, household members bargain over whom, if anyone, chauffeurs the child for school travel, while the utility function of the household ensues from explicit interactions. Thus, under these circumstances, overlooking heterogeneous intra-household interactions in travel models may lead to irrational results (Ho and Mulley, 2015a). Following the acknowledged importance of group decision-making analyses, the intra-household interaction is implicitly and explicitly coupled to travel demand models. Studies contribute implicitly (Vovsha and Petersen, 2005; Yarlagadda and Srinivasan, 2008) by entering household characteristics in individual decision models, and explicitly (Zhang and Fujiwara, 2006; Zhang et al., 2009) by presuming the effect of household members on household decisions to be context-independent.

Nevertheless, existing travel behavior models typically do not account for the cause and effect of intra-household bargaining mechanism on the escort decision of children in school trips. Understanding the role and behavior of household members in escorting children plays a pivotal role for two primary reasons. First, the school trips of children highly constrain activities of other household members, given that children have restrictions on mobility due to their age, level of income, and degree of personal freedom to travel (Yarlagadda and Srinivasan, 2008). Parents accompanying children to school adapt their daily plans to be consistent with their children's transport. If a child is not escorted to school, for instance, the parent may take transit to work. Hence, household interactions have to be considered in travel demand models for a more realistic prediction (Gliebe and Koppelman, 2005). Second, policies, such as stopping or launching school bus services for public schools and earlier school start times, alter the travel behavior of not only the students, but also other family members. Forming a conclusion based on the results of models without intra-household interaction misrepresents the impact of policies aiming at reducing unnecessary trips in daily routine's tours.

This paper tests a group decision-making model to examine the school travel behavior of students 6-18 years old in the Minneapolis-St. Paul Metropolitan area. The school trip information of 1,737 two-parent families with a student is extracted from Travel Behavior Inventory (TBI) data gathered by Metropolitan Council between the Fall 2010 and Spring 2012. The proposed model has four distinct characteristics including: (1) considering student explicitly in the model, (2) allowing for bargaining or negotiation among households, (3) quantifying the intra-household interaction among family members, and (4) determining the decision weight function for household members. This framework also covers a household with three members, namely, a father, a mother, and a student, but, unlike a whole host of studies, is not limited to dual-worker families. 
In the remainder of this paper we review the literature of escorting children in school trips. We then discuss the data used following a conceptual model of group decision-making. Subsequently we represent the results of the model and compare them with traditional microeconomic models. The penultimate section is dedicated to the sensitivity analyses of the household members' weight in various family structures. We conclude by broaching a number of issues that we believe should be addressed in future studies.

\section{LITERATURE SYNTHESIS}

Following the drastic reduction of independent mobility of students (Fyhri et al., 2011), research on escorting children to school has increasingly gained momentum. Previous studies (Mitra et al., 2014; Fyhri et al., 2011; Kyttä, 2004) have acknowledged the key role of independent mobility in heightening children's independency, maturity level, physical activity, and reducing traffic congestion. The emphasis on understanding the school-commuting behavior can be traced to 1990 in which Hillman et al. (1990) reported that the independent mobility of students had sharply dropped from 80 percent to 9 percent between 1971 and 1990 in the UK. More recently, school-commuting behavior has received attention, given its potential link to travel patterns of the parents and other adult household members (Ermagun and Samimi, 2015; Gupta et al., 2014).

As a result, a significant number of studies have been directed at exploring and modeling parental escort decisions. Table 1 summarizes the burgeoning literature on school-commuting behavior, while considering two main methodological orientations toward escort decisions: (1) studies of the travel patterns of children in an independent framework, and (2) studies of intrahousehold interdependencies between travel patterns of children and parents. While there is an influx of research on intra-household interactions in travel behavior of household members (Bradley and Vovsha, 2005; Gliebe and Koppelman, 2005; Srinivasan and Bhat, 2005; Meister et al., 2005) we focus on studies that analyzed exclusively school trips. Readers interested in intrahousehold interactions and group decisions in travel behavior more generally should see the special issues of Transportation (Bhat and Pendyala, 2005) and Transportation Research Part B (Timmermans and Zhang, 2009). An interesting literature review of intra-household interactions in transportation research is also found in Ho and Mulley (2015a).

Most commonly, econometrics frameworks use a single or joint probability distribution framework to obtain the coefficient of interest parameters. Lam and Loo (2014), for instance, studied the independent mobility of 2,110 children 6-12 years old in Hong Kong. Ermagun and Samimi (2016) developed a three-level nested logit model on 3,441 middle and high school students in Tehran. They elaborate how model misspecification misleads policy assessments: the elasticity of interest parameters in multinomial and nested logit models differ in both magnitude and sign in some cases.

Vovsha and Petersen (2005) played a pioneering role in exploring parental escort decisions in an intra-household interaction framework. Considering three escorting choices: (1) ridesharing with a household driver, (2) pure escorting with a household driver, and (3) no escort, they applied a nested logit model on children under 18 years old in Atlanta. Gender and work status of chauffeurs, car ownership, level of income, and distance to school turned out to have a meaningful effect in the final model. Yarlagadda and Srinivasan (2008), further, studied the parental escort decisions and travel mode choice of 4,352 children under 18 years of age, using data from the 2000 San Francisco Bay Area Travel Survey. To model escorting children and travel mode decisions in a simultaneous framework, they applied a multinomial logit model on a choice set of all possible combinations. Nine choice situations were constructed, namely: biking, 
driving, walking alone, walking with mother, riding a school bus, taking transit, driving with mother, driving with father, and driving with a non-parent driver. A wide variety of explanatory variables were found significant that included employment status of parents, vehicle ownership, level of income, age, ethnicity, and gender of the students, and distance to school. Susilo and Liu (2015), using the UK National Travel Survey from 2002 to 2006, studied the interaction between the travel patterns of parents, residential self-selectivity, and travel behavior of children. They found the travel behavior of the father does not have a significant effect on the children's travel, but the travel behavior of the mother is highly correlated with the children's travel. For instance, the more often the mother selects an active mode of travel, the greater the proportion of children will seek an active transportation mode.

Pertaining to the influential parameters, variables that affect escorting children to school might be divided into three characteristics, including students, households, and urban spatial and built environment. A positive correlation between the propensity of students riding to school and income, car ownership, and distance is unanimously confirmed in previous studies (Vovsha and Petersen, 2005; Yarlagadda and Srinivasan, 2008; Zwerts et al., 2010). The studies (Susilo and Waygood, 2012; Schwanen and Ettema, 2009; McDonald, 2007; McMillan, 2007) also pointed out environmental factors, ranging from urban form to social cohesion, are highly correlated with school travel behavior. Age is also shown to have a negative association with the likelihood of dependent travel to school (Carver et al., 2013; Samimi and Ermagun 2012). Further, female students are more likely to be driven to school (Yarlagadda and Srinivasan, 2008; Zwerts et al., 2010). Contradictory findings are reported about the role of siblings on the escort behaviors. Yarlagadda and Srinivasan (2008), for example, found an increase in the odds of children being driven to school with the presence of multiple students in a household. In contrast, McDonald (2008) noted an increase in the propensity of walking to school and a decrease in the likelihood of a student being driven, with the presence of multiple school-going children. Therefore, role of intra-household connections in students' escort behaviors deserve more investigation. Moreover, full-time workers are less likely to accompany their kids to school (Vovsha and Petersen, 2005; Yarlagadda and Srinivasan, 2008). The working status of mothers is more influential, as DiGuiseppi et al. (1998) found that a working mother favors the chance of students being driven.

Concretely speaking, group-decision making models emerged to relax the assumption of a unitary household utility function at the group level by including the utility of all members explicitly in the model. Existing research, however, has explored the intra-household interaction property implicitly by inserting the characteristics of parents, such as work status and time constraint, in the either individual or household decisions as an explanatory variable. Although this method captures the intra-household interactions to some extent, it does not reflect household members' attitudes toward parental escorting decisions.

The weight of the evidence suggests that the involvement of household members varies from household to household and within other household members. To identify the final decision, both mother and father play a significant role in the bargaining and negotiation process. This role is further determined by characteristics of parents. The more educated the mother, for example, the more power she has to make decisions for escorting children. Few studies have attempted to disentangle the "manic mums and distant dads" (Barker 2011) standpoint of who chauffeurs more, mother or father, in a statistical and modeling framework.

It has been long recognized that students, particularly when they get older, have a significant influence on achieving the final group decision during the decision-making process. Little is known, however, about the role of children in the travel decision making process. 


\section{DATA AND SAMPLE FORMATION}

In the vein of exploring accompaniment decision of students, we employ Travel Behavior Inventory (TBI) 2010 survey. The TBI was conducted by Metropolitan Council between the Fall 2010 and Spring 2012 to gather one-day travel information of over 14,000 households dwelling in the Minneapolis-St. Paul metropolitan area. We extracted 1,737 two-parent (one male and one female) families with one student 6-18 years old. Single-parent and non-traditional (non-nuclear) family structures have been filtered from this analysis, and will be examined in a companion paper. Other data requirements include: First, the school travel information of the child should be completed in the questionnaire. Second, there is a consistency among the report of parents and children about their escort patterns and their departure time. In other words, if a child is accompanied, the departure time of the child and the person who accompanied the child should be reported the same. We used three main characteristics for the parental escort decision analysis: (1) household characteristics, such as level of income, number of vehicles, and work status of parents, (2) students characteristic, namely age and gender, and (3) travel behavior information, including the travel mode and escorting pattern of children in school trips. Further, the existence of latitude and longitude of activity places enabled us to calculate the distance from home to school and merge the data with built environment variables. The explanation of variable used in the analysis is depicted in Table 2.

Five types of accompaniment, namely "with mother", "with father", "with siblings", "with other", and "alone" are considered in this study. Given the share of accompaniment with the both mother and father was less than one percent in our sample, we excluded this dual parental escort decision for the further analysis. Previous studies (Ermagun et al., 2015; Lam and Loo, 2014; Yarlagadda and Srinivasan, 2008) indicate that the behavior of children younger than 12 years old differ from the older school children. Younger children are less independent and their trips rely heavily on their parents. Hence, different models need to investigate the travel behavior of these age groups. The descriptive share of accompaniment types is outlined in Table 3 that is stratified by gender and age of students. The "pure escort" tour is defined as a situation in which the father or mother make a trip only to accompany their child in school trips. The "ridesharing" tour, on the other hand, means that students are accompanied in a work or educational tour of parents. As per Table 3, 11.8 percent of mothers produce a pure escort tour, while this number is 3.2 percent for fathers. The descriptive analysis implies that mothers are more willing to escort their child than fathers by about 13 percent in our sample.

Figure 1 shows the share of travel mode in each escorting group. When the mother or father decides to accompany their child, the dominant mode of travel is private vehicle. For instance, fathers, if accompany their 12-18 year old child, drive them to school in all observations.

\section{METHODOLOGICAL FRAMEWORK}

A multitude of statistical methods have been emerged in the literature to scrutinize the groupdecision making process. Assuming the group decisions to be context-independent, one may consider one of the group members as the decision maker and employs conventional choice models, including multinomial or nested logit models. Empirical evidence, however, reveals that household decisions are context-dependent, and are influenced from the preferences of all potential decision makers within the group (Zhang et al., 2009). Different household members, furthermore, may have diverse and even contradictory preferences toward a particular choice 
alternative (Zhang et al., 2009). Considering the unitary household approach overlooks the intrahousehold interactions. This approach, further, neglects other interpersonal effects, such as weight of household members in the final household decision and their considerations for other members. Zhang et al. (2009) proposed a group-decision making model to overcome the abovementioned deficiencies of unitary household approach. The framework used in this study adopts a similar approach with a main refinement. Students are explicitly considered in the final household decision.

Let $U_{h j}$ be the utility of alternative $j(j=1,2, \ldots, J)$ for the $h^{\text {th }}$ household $(h=1,2, \ldots, H)$ and $U_{h i j}$ be the utility of alternative $j$ for the $i^{\text {th }}$ member of household $h$. The group utility $\left(U_{h j}\right)$, is then measured by Equation 1.

$$
\begin{aligned}
& U_{h j}={ }_{i=1}^{I} w_{h i} u_{h i j}+{ }_{i=1 i>i}^{I} w_{h i} w_{h i} u_{h i j} u_{h i j}, \quad h=1, \ldots, H, j=1, \ldots, J \\
& w_{h i} 0 \quad \text { and } \quad{ }_{i=1}^{I} w_{h i}=1
\end{aligned}
$$

In this Equation, captures existence of intra-household interactions and may have any sign and any value. Moreover, the parameter $w_{h i}$ stands for the weight of $i^{\text {th }}$ decision maker for the household $h$ and is calculated by Equation 2. Where $Z_{h i}$ is the vector of attributes for $i^{\text {th }}$ decision maker of the household $h$, and ${ }_{i}$ is the vector of parameters associated with the attributes of decision maker $i$.

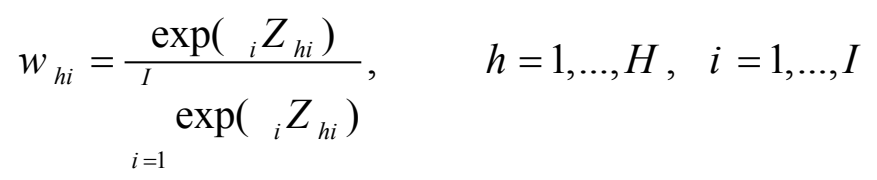

The $u_{h i j}$ includes both a deterministic term $\left(v_{h i j}\right)$ and an error term $\left(\varepsilon_{h i j}\right)$. Assuming that the error term of the alternative utilities follows the independent and identically distributed extreme value distribution, the choice probability of the group decision model is given in Equation 3. This easily follows the multinomial logit-type function of discrete choice model with group decision-making mechanisms obtaining under the principle of random utility maximization.

$$
P_{h j}=\frac{\exp \left({ }_{i=1}^{I} w_{h i} v_{h i j}+{ }_{i=1 i>i}^{I} w_{h i} w_{h i} v_{h i j} v_{h i j}\right)}{\exp \left(\sum_{i=1}^{I} w_{h i} v_{h i k}+{ }_{i=1}^{I} w_{i>i} w_{h i} v_{h i k} v_{h i k}\right)}
$$

Based on the choice probability formulation that is shown in Equation 3, the loglikelihood function is coded in STATA software and is maximized using the "BFGS" quasinewton optimization method as equation 4 (Train, 2009). In this equation, $y_{h j}$ is equal to 1 if household $h$ choose alternative $j$, and 0 otherwise. 


$$
L L(\beta)=\sum_{h 1}^{H} \sum_{j=1}^{J} y_{h j} \ln \left(P_{h j}\right)
$$

We postulate three main hypotheses:

- First, the travel behavior of children younger than 12 years old differs from children 12-18 years old (younger children are escorted more). Hence, the escorting patterns of them should be modeled independently.

- Second, the unitary household assumption misrepresents the influential parameters on escorting children, and overlooking the role of students in the household decision cloaks the real bargaining process in the family.

- Third, escorting students is unequally shared between father and mother (mother does more).

To test these hypotheses, we developed two models with and without the group-decision approach. For the model without the group-decision approach, we developed a multinomial logit model with the same parameters in the final group-decision model to make it more comparable. Further, the models are separately developed for the different age groups. As mentioned earlier, we are observing three decision makers (i.e. student, mother, and father) that are related to decisions on five alternatives (i.e. with mother, with father, with siblings, with others, and alone). The utility function of the alternative for each household member in choice set is defined as follows; where, $X_{h m}, X_{h f}$, and $X_{h c}$ are the attributes of the mother, father, and child, respectively. $Y_{h j n}$ stands for the attributes of the household and travel. $\beta_{m}, \beta_{f}, \beta_{c}, \theta_{n}, \gamma_{n}$, and $\varphi_{n}$ are unknown coefficients.

$$
\begin{aligned}
& \text { Mother: } v_{h j}=\sum_{m} \beta_{m} X_{h m}+\sum_{n} \theta_{n} Y_{h n} \\
& \text { Father: } v_{h j}=\sum_{f} \beta_{c} X_{h f}+\sum_{n} \gamma_{n} Y_{h n} \\
& \text { Child: } v_{h j}=\sum_{c} \beta_{c} X_{h c}+\sum_{n} \varphi_{n} Y_{h n}
\end{aligned}
$$

Simply, the logic behind the utility function specification follows four criteria:

- The variables are measured for all alternatives, except for the "with others" alternative.

- The characteristics of mother such as work status and her distance between school and workplace are only considered in the utility of mother. The same logic is applied for the utility of father and child.

- The household characteristics such as income and vehicle ownership are added in both utility of mother and father. The reason is these attributes are specifically held by parents and not the child.

- The travel characteristics including travel mode and distance are applied to the utility of all household members. 
The general modeling process allows the coefficient to vary across alternatives and utility of household members. However, when the value of the coefficients for a variable is close we used a generic approach across the utility of either alternatives or household members. For instance, the generic approach across the utility of household members is considered for the travel mode variables, due to no notable difference between the values. The final results of the group-decision and unitary household, multinomial logit, approaches are outlined in Tables 4 and 5 for the younger and the older age groups, respectively. The model development process builds on the finding of earlier studies, hypotheses, and parsimony considerations. The student's t-statistic is used to test for statistical significance of the null hypothesis.

As shown in Tables 4 and 5, most of the estimates are statistically significant with the hypothesized sign. Moreover, a likelihood ratio test is conducted to evaluate the overall goodness of fit for each model. Likelihood ratio index, also known as McFadden Pseudo $R^{2}$ fluctuates between zero and one, and has a similar interpretation as $R^{2}$ in the linear regression models.

To compare the prediction accuracy of the models, we divided the data into two parts for both students aged 6-12 and 12-18 years old. We randomly selected 70 percent of the data to develop the models. The rest is then used for comparing the prediction power of models. The results are depicted in Table 6. In overall, the multi-linear group decision model is better than multinomial logit model by about 6 percent. However, by looking at more detailed prediction measures for each category escort pattern, it can be seen that the multi-linear group decision model performs better than the multinomial logit model by 15 percent in some cases. It emphasizes the importance of considering intra-household interaction and weight factor of household members in the analysis. However, it is worth mentioning that the low prediction power of models in a few cases is due to the small sample size in those categories. Lack of enough data for the training phase diminishes the accuracy of prediction in the test phase.

\section{DISCUSSION}

\subsection{What is the household utility function?}

The effects of students, parents, and household characteristics on parental escort decisions are separately investigated for mothers, fathers, and children in a simultaneous framework. Having to do with household's characteristics, full-time working fathers are less likely than mothers to escort their child. It is consistent over both students 6-12 and 12-18 years old. Full-time working mothers, however, have a higher probability of escorting their children aged 6-12 years, but not 12-18 years. It is also worth mentioning that full-time working parents prefer that the parental counterpart accompanies their child in school trips. Our results add that while the probability of escorting children by their father is low for full-time working fathers, full-time working mothers despite the inflexible schedule do care for their younger children more than fathers.

Contradictory results are found among children 6-12 and 12-18 years old for the influence of the number of vehicles on the parental escort decisions. The dummy variable of "Vehicle 2+" in utility indicates that in households with more than one vehicle, mothers are more probable to escort their 6-12 years old children. This variable, as expected, has a negative correlation with escorting the 12-18 years old children. This variable is not significantly correlated with the utility of escorting with father. As expected, the utility of independent travel is increased in this families for the children aged 12-18 due to having driver's license. 
In regard to student's characteristics, older students are less willing to be accompanied by either parents or siblings in both age groups. The results are similar in sign but not magnitude between both age groups. In other words, increasing the age in the older age group reduces the probability of escorting with either parents or siblings significantly more than the younger age group. The results also designate that mothers have a higher probability to escort their boy aged 6-12 years than a similarly aged girl student. It shows the dual behavior of mothers toward boys and girls in different age groups. For students younger than 12 years old, mothers take care of boys more than girls in school trips. However, for students older than 12 years old, they express more concerns about their girls.

Having to do with travel behavior characteristics, using private vehicles in school trips increases the probability of escorting, particularly with parents in both age groups. For the children aged 6-12 years, however, fathers are more probable to accompany their children by car than mothers. The results are consistent with descriptive observation. Using the school bus, unsurprisingly, increases the probability of escorting with other and independent travel. Studies (Ermagun et al., 2015; Yarlagadda and Srinivasan, 2008) reveal that the travel behavior in school trips varies greatly, depending on distance from school. However, we hypothesize that it has a different effect among household members. The results imply that students aged 6-12 years have a lower probability to travel alone by increasing the home-to-school distance. However, we found a positive correlation between home-to-school distance and independent travel among students aged 12-18 years. Interestingly, by increasing the home-to-school distance mothers and fathers prefer that their child is accompanied by father and mother, respectively. The finding is similar between both age groups. Not only does home-to-school distance affect travel behavior of students, but we hypothesize that the distance from parents' work and school influences escorting patterns. We found increasing the distance between school and parents' workplace is negatively correlated with the probability of accompaniment. In this case, parents prefer that the other parent takes care of their child.

\subsection{Who are decision makers?}

One of the main aims of this research is to investigate the role of household members in making the final parental escort decision or in the bargaining process. The majority of studies in the consumer behavior arena, to simplify the calculation, reflect a constant term for the weight of household members. Having this assumption, a general type of household utility function, compromise type, emerges in which household members have the same weight. However, we believe that the weight of household members is linked to the characteristics of members, including education, gender, and age. To relax the constant weight assumption, a utility is separately considered for the weight of mother, father, and child in households. The gender and age of students were found statistically significant in the weight utility of students. The results show the weight of girls is more than boys among children aged 6-12, while there is not a significant deference in the older age group. Girls, on average, mature earlier than boys, which may beget this dissimilarity. In both age groups, the weight of students in the final decision is increased by increasing age. This effect, however, is stronger among students aged 12-18 years old. The effect of the "M_High Educ" and "F_High Educ" variables implies that the more highly-educated the mother and father, the more probable to dominate the parental escort decision for the younger age group. However, there is not a significant effect of highly-educated parents among the older age group. 
To give the reader an idea of the rough weight of household members in making escort decision, the weight of members was averaged over observations. Figure 2 shows the weight of household members among different strata of families for both age groups. As shown in Figure 2, the utility of father, on average, has 34.80 and 33.16 percent weight in the final decision for children aged 6-12 and 12-18 years, respectively. Although there is not a significant difference between the weight of mothers and fathers, the mother has slightly a higher probability to dominate the decision of escorting children aged 6-12 years in school trips which may derive from her concern for her younger child. For the children aged 12-18 years, however, the father is more likely to dominate the decision of escorting children. Interestingly, the weight of students is notably increased among the older group. The finding reveals that children aged 12-18 years have a significant effect, even more than mothers, on their travel behavior in school trips. It is also worth noting that studies proposed exploring the travel behavior of students in different age groups. The main reason is rooted deeply in the fact that children younger than 12 years old are less independent and thereby need a separate analysis. Figure 2, furthermore, portrays the effect of social strata on the weight of families. We hypothesized that the weight of household members varies from family to family. The findings, nevertheless, pinpoint that there is not a significant difference between families pursuant to Figure 2.

\subsection{Sensitivity analysis and model specification}

This section compares the results of unitary household and group-decision making approaches. In this vein, the elasticity of interest parameters is measured for the developed multinomial logit and group-decision making models. Further, the elasticity of parameters is discussed to give the reader a quantitative insight into the effects of variables. Table 6 shows the elasticity of interest parameters derived from both group-decision and unitary household approaches. The elasticity of the continuous variable, namely age and distance, is measured at its average value over the sample. Effects of dummy variables, however, were computed as the percentage change in escorting choice probability when the value is changed from 0 to 1 . The elasticity results for the younger children show a one percent increase in their age diminishes the probability of escorting with mothers and fathers by 1.01 and 1.34 percent, respectively. This effect is significantly higher among the older children. A one percent increase in the age of the older children reduces the probability of escorting with mothers and fathers by 3.11 and 3.98 percent, respectively. Hence, neglecting the effect of age within different age groups may mislead.

In families with more than one vehicle, the probability of escorting with mother increases by 16.37 percent among the younger group, while diminishes by 38.18 percent among the older group. The same trend is found among the older group. Studying the younger group, the probability of escorting with fathers increases by 112.24 percent when the mothers work fulltime. However, the probability of escorting with fathers decreases by 121.46 percent when the fathers have a full-time job, and thereby mothers accompany their kids with the probability of 53.31 percent. An interesting difference is seen among the older children. When mothers have a full-time job, the probability of escorting with mothers significantly declines compared with the younger age group. Further, the probability of escorting with fathers only increases by 31.21 percent. Interestingly, a one percent increase in the home-to-school distance increases the probability of escorting with mother by 0.66 percent among the younger group of children. Among the older group of children, however, a one percent increase in the home-to-school distance decreases the probability of escorting with mother by 0.25 percent. It shows mothers have more concern about their younger child. The elasticity of this variable for escorting with 
fathers is -0.19 and -0.31 for the students aged $6-12$ and $12-18$ years, respectively. The elasticity results also indicate that a 1 percent increase in the distance between school and mothers' workplace decreases the probability of escorting with mothers by 0.47 and 0.73 among the younger and older group, respectively. However, a 1 percent increase in the distance between school and fathers' workplace decreases the probability of escorting with fathers by 0.73 and 0.81 among the younger and older group, respectively. It emphasizes again that mothers take care of their child more than fathers. Similarly, it is interesting to follow the rest of the results from Table 6 .

As stated earlier, overlooking the intra-household interaction in the modeling begets either overestimation or underestimation. A comparison is made between the elasticities derived from the group-decision and unitary household models to make the differences tangible. The ratio of group-decision and unitary household elasticities are calculated to observe the magnitude of difference between the two models. To calculate the ratio, the elasticity value of unitary household is divided by the group-decision elasticity, and the cumulative distribution function of this ratio is plotted in Figure 3. The elasticities differ not only in the value, but in the sign in some cases. As Figure 3, the elasticities differ in the sign in 10 percent of the cases. The findings show that in 63 percent of situations the unitary household approach underestimates the results. Among the younger age group, the magnitude of this misrepresentation fluctuates between 1.0 and 3.2. Among the older age group, this misrepresentation fluctuates between 1.1 and 2.7. As shown in Figure 3, the elasticities of unitary household model either overestimate or underestimate as large as 2 times more than that of the group-decision model in 20 percent of cases. The significant difference between the elasticities shouts for the importance of intrahousehold interactions. It is a direct consequence of model misspecification that misleads both long-term and short-term policies.

\section{CONCLUSION AND IMPLICATIONS FOR FUTURE STUDIES}

A household is the most fundamental group that exemplifies interrelated behaviors. There are fundamental differences between individual and group decision-making behavior. The group decision-making mechanism must:

1. capture complexity of travel behavior,

2. reflect heterogeneous intra-household interactions,

3. allow bargaining and negotiation, and

4. relax the benevolent dictator assumption.

Although the first two characteristics have been examined in detail, the others need more analysis in school travel. Concretely speaking, mother, father, and child specify the utility of each alternative with respect to utilities of other members of the household. The way of involvement, then, reflects the influence of household members on household choice probability. The introduction of school bus, for instance, affects not just the travel behavior of children, but the travel patterns of parents. Parents concerned with the safety of their child and with a free time schedule are more likely to generate a pure escorting tour. While finding a safe school bus service, the parents allow their child an independent trip, and thereby cancel the unnecessary trips. Despite the role of such knowledge in planning and policy implications, little is known about the group-decision making process for escorting children in school trips. This empirical 
study, therefore, attempted to fill the gaps by applying a heterogeneous group decision-making mechanism on parental escort decisions.

The group-decision model developed in this study underscores the need to accommodate intra-household interaction and children for realistic policy evaluations. We conclude that ignoring the intra-household interaction for parental escort decisions and building on the results driving from the unitary household approach is misleading. The elasticity analysis of interest parameters shows not just the results of both models differ significantly in magnitude, but the sign of coefficients are flipped in some cases. The results for instance, indicate that school children aged 6-12 years are less likely to accompany by their mother in low income families. The unitary household model, however, shows a positive correlation. This is a direct consequence of model misspecification where the intra-household interaction is disregarded in analyses. Additionally, students, particularly the older group, play a key role in escorting decisions. Hence, they should be explicitly considered in the analysis to reflect the reality. Overlooking the role of students, in our case, results in larger than 2 times misrepresentation of the effect of parameters in 20 percent of cases.

This paper necessitates the group-decision making approach encompassing the weight factor of household members in school travel analysis. Due to the lack of data, this study has room to improve with further research:

- How do parental reservations, such as travel mode safety, security, and reliability affect mode choice decision while considering the group-decision making approach?

- How do family structures, namely single-parent, two-parent, and non-traditional families behave to escort their children in school trips?

- How do built environment variables, including density of green space, school, sidewalk and other land-use variables switch the parental attitudes toward escorting decisions?

- How do the escorting decisions change for return trips from school?

- How do policies such as school bus availability free bus passes affect the escort pattern of the students?

\section{ACKNOWLEDGEMENTS}

We highly appreciate constructive comments of the two anonymous referees which helped to improve the paper.

\section{REFERENCES}

Barker, J., 'Manic Mums' and 'Distant Dads'? Gendered geographies of care and the journey to school. Health \& place, Vol. 17, No. 2, 2011, pp. 413-421.

Bhat, C. R. and R. M. Pendyala, Modeling intra-household interactions and group decision making. Transportation, Vol. 32, No. 5, 2005, pp. 443-448.

Bradley, M., \& Vovsha, P. (2005). A model for joint choice of daily activity pattern types of household members. Transportation, 32(5), 545-571.

Carver, A., A. Timperio, and D. Crawford, Parental chauffeurs: what drives their transport choice? Journal of Transport Geography, Vol. 26, 2013, pp. 72-77.

Deka, D., An explanation of the relationship between adults' work trip mode and children's school trip mode through the Heckman approach. Journal of Transport Geography, Vol. 31, 2013, pp. 54-63. 
DiGuiseppi, C., I. Roberts, L. Li, and D. Allen, Determinants of car travel on daily journeys to school: cross sectional survey of primary school children. Bmj, Vol. 316, No. 7142, 1998, pp. $1426-1428$.

Elias, W. and R. Katoshevski-Cavari, The role of socio-economic and environmental characteristics in school-commuting behavior: A comparative study of Jewish and Arab children in Israel. Transport Policy, Vol. 32, 2014, pp. 79-87.

Ermagun, A., \& Samimi, A. (2016). How Are Children Accompanied to School?. Journal of Urban Planning and Development, 04016002.

Ermagun, A., \& Samimi, A. (2015). Promoting active transportation modes in school trips. Transport policy, 37, 203-211.

Ermagun, A., Rashidi, T. H., \& Lari, Z. A. (2015). Mode choice for school trips: long-term planning and impact of modal specification on policy assessments. Transportation Research Record: Journal of the Transportation Research Board, (2513), 97-105.

Ermagun, A., T. Hossein Rashidi, and A. Samimi, A joint model for mode choice and escort decisions of school trips. Transportmetrica A: Transport Science, Vol. 11, No. 3, 2015, pp. 270-289.

Fortin, B. and G. Lacroix, A test of the neoclassical and collective models of household labour upply, 1993.

Fyhri, A., R. Hjorthol, R. L. Mackett, T. N. Fotel, and M. Kyttä, Children's active travel and independent mobility in four countries: Development, social contributing trends and measures. Transport Policy, Vol. 18, No. 5, 2011, pp. 703-710.

Gliebe, J. P., \& Koppelman, F. S. (2005). Modeling household activity-travel interactions as parallel constrained choices. Transportation, 32(5), 449-471.

Gupta, S., P. Vovsha, V. Livshits, P. Maneva, and K. Jeon, Incorporation of Escorting Children to School in Modeling Individual Daily Activity Patterns of HouseholdMembers. Transportation Research Record: Journal of the Transportation Research Board, , No. 2429, 2014, pp. 20-29.

He, S. Y., Will you escort your child to school? The effect of spatial and temporal constraints of parental employment. Applied Geography, Vol. 42, 2013, pp. 116-123.

Hillman, M., J. Adams, and J. Whitelegg, One false move. Policy Studies Institute. www.psi. org. uk/publications/publication.asp, 1990.

Ho, C. and C. Mulley, Intra-household interactions in transport research: a review. Transport Reviews, Vol. 35, No. 1, 2015a, pp. 33-55.

Ho, C., \& Mulley, C. (2015b). Intra-household Interactions in tour-based mode choice: The role of social, temporal, spatial and resource constraints. Transport Policy, 38, 52-63.

Kyttä, M., The extent of children's independent mobility and the number of actualized affordances as criteria for child-friendly environments. Journal of environmental psychology, Vol. 24, No. 2, 2004, pp. 179-198.

Lam, W. W. and B. P. Loo, Determinants of children's independent mobility in Hong Kong. Asian transport studies, Vol. 3, No. 2, 2014, pp. 250-268.

Larsen, K., J. Gilliland, P. Hess, P. Tucker, J. Irwin, and M. He, The influence of the physical environment and sociodemographic characteristics on children's mode of travel to and from school. American Journal of Public Health, Vol. 99, No. 3, 2009, p. 520.

Lin, J.-J. and H.-T. Chang, Built environment effects on children's school travel in Taipai: independence and travel mode. Urban Studies, Vol. 47, No. 4, 2010, pp. 867-889.

McDonald, N. C. and A. E. Aalborg, Why parents drive children to school: implications for safe routes to school programs. Journal of the American Planning Association, Vol. 75, No. 3, 
2009, pp. 331-342.

McDonald, N. C., Household interactions and children's school travel: the effect of parental work patterns on walking and biking to school. Journal of transport geography, Vol. 16, No. 5, 2008, pp. 324-331.

McDonald, N. C. (2007). Travel and the social environment: Evidence from Alameda County, California. Transportation research part D: transport and environment, 12(1), 53-63.

McMillan, T. E. (2007). The relative influence of urban form on a child's travel mode to school. Transportation Research Part A: Policy and Practice, 41(1), 69-79.

Meister, K., Frick, M., \& Axhausen, K. W. (2005). A GA-based household scheduler. Transportation, 32(5), 473-494.

Mitra, R., G. E. Faulkner, R. N. Buliung, and M. R. Stone, Do parental perceptions of the neighbourhood environment influence children's independent mobility? Evidence from Toronto, Canada. Urban Studies, 2014, p. 0042098013519140.

Motte-Baumvol, B., O. Bonin, and L. Belton-Chevallier, Who escort children: mum or dad? Exploring gender differences in escorting mobility among parisian dual-earner couples. Transportation, 2015, pp. 1-19.

Samimi, A., \& Ermagun, A. (2012). Students' tendency to walk to school: Case study of Tehran. Journal of Urban Planning and Development, 139(2), 144-152.

Schwanen, T., \& Ettema, D. (2009). Coping with unreliable transportation when collecting children: examining parents' behavior with cumulative prospect theory. Transportation research part A: Policy and Practice, 43(5), 511-525.

Srinivasan, S., \& Bhat, C. R. (2005). Modeling household interactions in daily in-home and outof-home maintenance activity participation. Transportation, 32(5), 523-544.

Susilo, Y. O., \& Liu, C. (2015). The influence of parents' travel patterns, perceptions and residential self-selectivity to their children travel mode shares. Transportation, 1-22.

Susilo, Y. O., \& Waygood, E. O. D. (2012). A long term analysis of the mechanisms underlying children's activity-travel engagements in the Osaka metropolitan area. Journal of transport geography, 20(1), 41-50.

Timmermans, H. J., \& Zhang, J. (2009). Modeling household activity travel behavior: Examples of state of the art modeling approaches and research agenda. Transportation Research Part B: Methodological, 43(2), 187-190.

Train, K. E. (2009). Discrete choice methods with simulation. Cambridge university press.

Vovsha, P. and E. Petersen, Escorting children to school: statistical analysis and applied modeling approach. Transportation Research Record: Journal of the Transportation ResearchBoard, No. 1921, 2005, pp. 131-140.

Yarlagadda, A. K. and S. Srinivasan, Modeling children's school travel mode and parental escort decisions. Transportation, Vol. 35, No. 2, 2008, pp. 201-218.

Zhang, J. and A. Fujiwara, Representing household time allocation behavior by endogenously incorporating diverse intra-household interactions: A case study in the context of elderly couples. Transportation research part B: methodological, Vol. 40, No. 1, 2006, pp. 54-74.

Zhang, J., M. Kuwano, B. Lee, and A. Fujiwara, Modeling household discrete choice behavior incorporating heterogeneous group decision-making mechanisms. Transportation Research Part B: Methodological, Vol. 43, No. 2, 2009, pp. 230-250.

Zwerts, E., G. Allaert, D. Janssens, G. Wets, and F. Witlox, How children view their travel behaviour: a case study from Flanders (Belgium). Journal of Transport Geography, Vol. 18, No. 6, 2010, pp. 702-710. 